
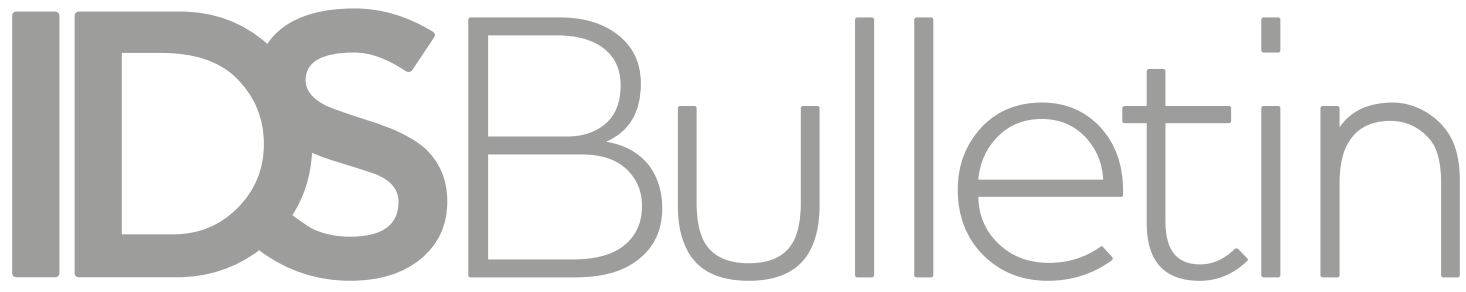

Transforming

Development Knouledge

Volume 48 | Number 1A | October 2017

\title{
HAS UNIVERSAL DEVELOPMENT COME OF AGE?
}

\section{Editor Richard Longhurst}

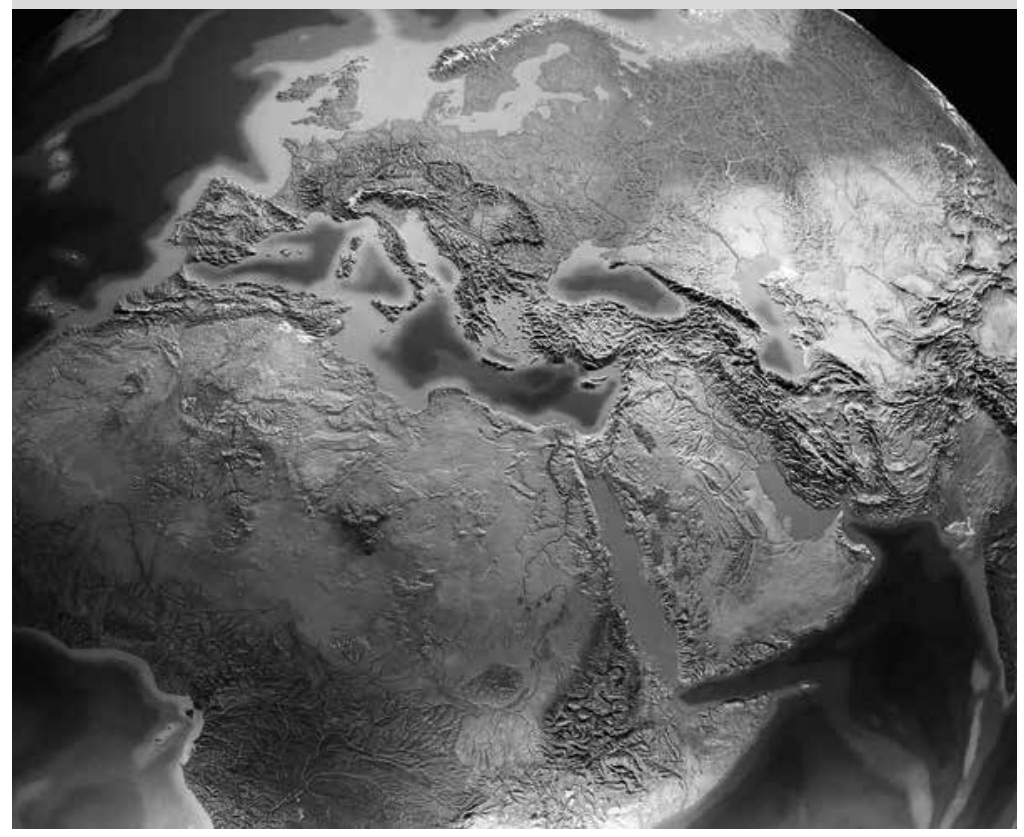




\section{Contents}

Introduction: Universal Development - Research and Practice

Richard Longhurst $\quad$ Article first published October 2017, IDSB48.1A

Editorial: Britain: A Case for Development?

Richard Jolly and Robin Luckham Article first published December 1977, IDSB9.2

Back to the Ivory Tower? The Professionalisation of Development Studies and their

Extension to Europe

Dudley Seers

Article first published December 1977, IDSB9.2

Redistribution with Sloth - Britain's Problem?

Richard Jolly Article first published December 1977, IDSB9.2

Keynes, Seers and Economic Development

H.W. Singer

Article first published July 1989, IDSB20.3

Poverty and Social Exclusion in North and South

Arjan de Haan and Simon Maxwell Article first published January 1998, IDSB29.1

Comparisons, Convergence and Connections: Development Studies in North and South Simon Maxwell

Article first published January 1998, IDSB29.1

Poverty, Participation and Social Exclusion in North and South

John Gaventa

Article first published January 1998, IDSB29.1

Introduction: New Democratic Spaces? The Politics and Dynamics of Institutionalised

Participation

Andrea Cornwall

Article first published April 2004, IDSB35.2

Power, Participation and Political Renewal: Issues from a Study of Public

Participation in Two English Cities

Marian Barnes, Helen Sullivan, Andrew Knops and Janet Newman

Article first published April 2004, IDSB35.2

Development Research: Globalised, Connected and Accountable

Lawrence Haddad

Article first published March 2007, IDSB38.2 


\section{Power, Participation and Political Renewal: Issues from a Study of Public Participation in Two English Cities}

Marian Barnes, Helen Sullivan, Andrew Knops and Janet Newman

\section{Introduction}

Contemporary interest in citizen engagement in public policy stems from a concern with the governance and quality of public service delivery, with improving the legitimacy of decision making and with articulating the claims of those previously marginalised (Barnes and Bowl 2001; Newman 2001; Sullivan and Skelcher 2002). This article discusses recent research into the diversity of sites and practices of public participation in two contrasting English cities, Birmingham and Liverpool. ${ }^{1}$ It explores the perspectives of citizens and officials on participation and examines the construction of "the public", the negotiation of legitimacy and how questions of difference and diversity are managed in spaces for participation. Our analysis reflects on issues of interaction and institutional design within forums for public involvement, the interaction between representative and participative democracy in the public policy field and how the tensions between representative and participative democracy are reconciled, or not.

\section{Citizenship and participation in service delivery}

Shifting notions of citizenship and the merits of participation have informed successive attempts by UK governments to involve the public in policymaking over service delivery. In the 1970s, spatially targeted Community Development Projects (CDP) sought to involve citizens as empowered partners in their dealings with the state, a programme which ultimately failed to shift the prevailing balance of power (Cockburn 1977). The 1980s saw a dramatic shift in emphasis as Conservative governments promoted the notion of the "citizen as consumer". This privatisation of the relationship between the citizen and the state was supported by the outsourcing of local services and the expansion of private provision in key areas of public concern. The public were encouraged to play an active role in assessing service quality (through satisfaction surveys and charter initiatives) and contributing to service management (through participation in school governing bodies and forms of tenant management). The empowerment of citizenconsumers was considered important in challenging the dominant self-interest of ruling politicians and professionals at the local level (Prior et al. 1995).

The inadequacy of the Conservatives' individualised conceptualisation of citizens as consumers led to an emphasis in the latter years of the twentieth century on the responsibilities of citizens to contribute to creating their own and others' welfare (Barnes and Prior 2000). This position was developed under the New Labour administration that took power in 1997 and is reflected in their publicised priorities for reform. These included measures that sought to reconnect the citizen to the state, revitalising the democratic health of the nation and included efforts to involve the public at all levels of government through instruments such as referendums, citizens' juries and panels, youth councils, neighbourhood forums and interactive websites.

New Labour sought to engage service users as participants in measures to improve the performance of public services, whether through "Best Value" at local government level or the Patient Advocacy and Liaison Services (PALs) in the health 
service, which was heralded as a voice for users in service planning. Resources were targeted at disadvantaged or socially excluded communities through particular programmes contained within the National Strategy for Neighbourhood Renewal (Social Exclusion Unit 2001; see Taylor this Bulletin). The rapid increase in recent years in the volume and range of non-electoral participation initiatives used by local government has seen methods such as public meetings now more likely to be used alongside user-oriented mechanisms like focus groups and more innovative approaches such as interactive websites or citizens' juries (Lowndes et al. 1998; ODPM 2002). In 2001, 14 million people were estimated to have participated in these exercises (ODPM 2002).

Public participation in public policy, however, is not simply a response to government prompting and promotion but also emanates from autonomous community action and social movements, from claims for the authentic expression of lived experiences, which have gone unheard or been actively silenced (e.g. Barnes and Bowl 2001). Sometimes couched in terms of creating opportunities for more active citizenship (e.g. Barnes 1997; Lister 1997), the concern here is to create opportunities for people excluded from decision making to become empowered and to influence decisions that affect their lives (Melucci 1996; Touraine 2000; Fraser 1997). Our study sought to assess the capacity of these new spaces for participation in public policy (whether stimulated by government or autonomous citizen action) to contribute to democratic renewal and challenge social exclusion. ${ }^{2}$ In particular, we sought to understand better the kinds of fora that exist at the local level, who participates in them, how issues of difference and dissent are handled and how participants engage with the 'rules of engagement' within these spaces. ${ }^{3}$

\section{The range and types of deliberative forums at the local level}

Our mapping of public participation in the two cities provided evidence of a wide range of initiatives. The majority of reported initiatives could be characterised as "invited spaces", serving to bridge the gap between the citizen and state. This is not surprising given that most of our informants were officials from the local government or health sectors, many of whom were engaged in developing these "invited spaces". However, we also obtained information about a small number of relatively longstanding "popular spaces" through our voluntary and community sector informants. It is possible to characterise these initiatives in the following ways although many of the reported initiatives could be included in more than one of the categories below:

- Initiatives to address cross-cutting issues such as the Sustainability Forum in Birmingham (environmental initiative established in response to Local Agenda 21), Communities Against Poverty in Liverpool and a wider range of regeneration partnerships in both cities.

- Initiatives that focused on issues affecting a specific population group/s including the Senior Citizens' Forums in both cities, the Lesbian and Gay Forum in Liverpool, the Black and Minority Ethnic Group Council and the Search Team (disabled and other service users) in Birmingham. These initiatives may be city-wide or neighbourhood-based such as the initiative to develop services for Asian young people as part of an area-based regeneration programme in Birmingham.

- Generic forums for involvement led by the local authority but involving the public and partners from other sectors namely the Local Involvement, Local Action (LILA) initiative in Birmingham and Area Committees in Liverpool.

- Advocacy initiatives stimulated by community or voluntary action to improve services or secure policy change, such as the Liverpool Mental Health Consortium, Communities Against Poverty and the Birmingham Women's Advice and Information Centre.

- Service-specific initiatives including Patients Forums/Councils in hospitals in both cities, a Women's Information Network for maternity services in Liverpool, Best Value consultations by local government departments, tenant participation initiatives relating to housing and Primary Care Group involvement activities (in both cities).

- Area-specific initiatives including Education Action Zones (improving school attainment levels in targeted areas) and Sure Start (working with children aged 0-4) in both cities, Neighbourhood Services Pilots (a decentralisation scheme) and 
the West Everton Community Council (a community-led organisation) in Liverpool and the Family Support Strategy in Birmingham.

- Issue-specific initiatives such as the redevelopment of a park in Birmingham and the community action to prevent the closure of a health centre in Liverpool.From our initial mapping exercise, it was possible to identify three key features of the reported local public participation initiatives: a neighbourhood focus, an intention to extend and enhance participative democracy and the building of social capital.

\section{The neighbourhood focus}

Motivation for public participation could be found from locality to supra-national level in both cities. Evidence of a shift towards neighbourhood-based activity was provided most obviously by the "New Deal for Communities" regeneration programmes in both cities. This programme targeted activity and resources at place-based communities of no more than 8,000 people. The combination of policies and programmes from national and supra-national bodies also had a neighbourhood focus. Locally generated policies and programmes supported this neighbourhood momentum and the local government organisations in both cities had devised decentralisation programmes that aimed to devolve decision making to sub-local level.

However, other dimensions to involvement cut across this neighbourhood focus. In the National Health Service (NHS), these related to specific service sites, such as hospital or surgery patients' councils, or types of health problem, such as mental health or diabetes. Participation was also organised around communities of identity, the strongest example of which was a city-wide lesbian and gay community police forum, although other examples are outlined above. Finally, both cities paid attention to super-ordinate issues that affected all communities. For example, in one city, there was a city-wide sustainability forum, while in another, a "Communities Against Poverty" forum reflected a concern with deprivation.

\section{Extending and enhancing participatory democracy}

Participation initiatives in both cities were designed to involve citizens in all stages of the policy process from design to implementation and evaluation, through three main modes of engagement:
1. Information giving, either as a means to wider participation, or to raise awareness about the nature of a particular service or function.

2. Consultation, an opportunity for the public to express views about a particular issue within a framework set by a service delivery organisation.

3. Dialogue, or deliberation, between organisations and citizens, in which issues for discussion could be introduced by both parties.

In most cases, a number of methods were combined to extend and enhance participation. The most commonly employed was the small group, normally as part of a combination of other techniques. Other methods included visioning events, focus groups and citizen research. Certain circumstances called for very particular methods, so teleconferencing was used for a group of cystic fibrosis sufferers who could not meet face to face because of the risk of cross infection. Social networks in pubs and clubs had been used to access the views of the lesbian and gay community.

\section{Building social capital}

There was evidence that building collective capacity among specific communities informed the design of some participation initiatives. This developmental capacity had two emphases. The first concentrated on building the capacity of groups and institutions to relate to each other. Activity here was targeted at improving the understanding between communities and institutions of each others' ways of operating. Here Black and minority ethnic communities were most frequently identified as target groups as they were often perceived to be the most marginalised from existing decision-making processes. However, the issue also arose in relation to the setting up of a new health organisation, a primary care group, where key officials were conscious that the reproduction of 'the traditional ways of doing things' would not attract community members to participate.

The second related to building individuals' capacity within communities. Activities here tended towards providing opportunities for individuals to associate with each other as well as officials, to exchange information and share personal experiences and to build personal relationships through the process of association and exchange, for example, an initiative providing support for carers was as much about developing a strong 
network amongst potentially isolated carers as it was about accessing carers' experiences to inform future policy and service delivery decisions.

\section{Who takes part and why?}

Many of those involved had previous experience of "activism" including within trades unions, political parties, voluntary organisations, self-help groups or community action. Some officials shared similar histories with community members illustrating the way in which the experiences of different stakeholders frequently overlapped or were held in common. Participants could be considered to be motivated on a range of different "commitments", including:

- Commitment to an area, for example, young people involved in a regeneration initiative saw this as an opportunity to improve the area in which they lived.

- A religious commitment that provided a value base leading to social action to improve people's lives.

- A commitment to a cause about which people could become very knowledgeable, for example, amongst both citizens and officials involved in an Agenda 21 initiative.

- An awareness of being a representative of "a people". For example, a Yemeni man who saw his role as ensuring that the voices and experiences of the Yemeni population were heard to improve the lives of older people.

- Lifelong commitment to causes, such as party political, trade union, peace campaigns, women's groups, deriving from political commitments or professional backgrounds.

- Commitments originating in experiences of difference, exclusion or disadvantage, including poverty, disability, or differences related to sexuality, gender or ethnicity.

To dismiss people demonstrating such commitments as "self interested" is too simplistic (see Young 2000). Nevertheless, it is important not to ignore the potential for new forms of participation to reproduce exclusions. This is a point we address below.

Different "opportunity structures" for participation are created by public bodies. Initial survey data suggested two forms. The first emphasised the desire for "openness" within a given population group, most commonly, residents living in a specific area (such as area committees); users of a particular service (such as community care services); or citizens sharing particular characteristics (such as the lesbian and gay forum). The second emphasised the idea of "representation". Here membership was created by eliciting "representatives" from existing groups and organisations, for example, the Minority Ethnic Group Council (MEGC) established by an NHS Trust, in which membership was formed by invitation to ethnic community organisations.

More detailed analysis of the initiatives in our case studies suggested that these two principles were overlaid in quite complex ways. For example, those forums constituted through the principle of representation could be more or less open in terms of the field from which representation was sought. In the MEGC, for example, only organisations recognised by the local health trust were invited to send representatives. There was, as one member termed it, an 'unofficial hierarchy structure' of representation.

Data suggested that the tension between "openness" and "representation" was resolved through the use of informal networks to extend membership. This led to a number of difficulties. In some forums, an imbalanced membership resulted, with some groups significantly underrepresented because an absence of networks to existing membership created a barrier to participation. Our detailed studies of individual initiatives revealed different ways in which groups dealt with the desire for membership to be "open", while ensuring that particular groups were represented and a diversity of voices heard. Some groups sought to resolve this by creating more formally constituted decision-making groups within an open membership. But this did not necessarily resolve the difficulties because of the problems of securing nominations for election or applications for appointment. Our data suggested that problems of securing both membership and office holding are shaped by the interaction between institutional context and individual motivations.

Questions of legitimacy informed the way in which opportunity structures were created, the forms of power and influence that operated within forums and between forums and decision-making bodies. Whatever the formal membership rules (see below), informal claims to legitimacy tended to be 
based on the skills, knowledge and experience of particular members and/or their claims to "represent" a wider constituency. For example, in locality based forums, knowledge of the locality was highly valued. But while notions of "the general public" or "local residents" were used by officials and lay members to denote the absence of sectoral interests, in practice many lay advisory members were not "just residents", some were professionals viewed as having their own agendas.

"Representation" was a key discourse in claims for legitimacy. Interviews highlighted the ways in which "representation" and "representativeness" informed official expectations about who should be involved and how. But our studies showed that citizens also drew on a range of notions of representation to define their position within the forums and to establish the legitimacy of their claims by reference to external publics. For example, in a service user's forum individuals were invited to join on the basis of (1) their capacity to represent service users' views by virtue of their own experience; (2) their capacity to represent particular user groups, for example disabled people; (3) their capacity to represent other service users through contact with them. The tensions between these different claims were resolved in part by creating a distinction between representation of people and representation of issues.

Conflicting claims may underpin struggles for legitimacy within and between forums. This was evident in the youth conference study, where council youth workers sought to impose an inclusive view of the young people to be involved in planning the conference, in the face of claims put forward by an existing autonomous youth forum that they were the legitimate representatives of local youth. This study illustrates the tensions between officially espoused adherence to recognising diversity and deeply embedded assumptions about what constitutes a legitimate community. Here an attempt by city council workers to widen the range of groups involved in planning the conference served to question the legitimacy of the original forum to speak on behalf of all local young people. The forum's legitimacy claim came not from a formal process of election, nor from claims to be representative of all young people in the area, but from a shared history of action.

Autonomous groups can face problems as they engage with institutional forums in which officials claim the right to define membership. Such groups may then be faced with a choice about whether they reconstitute themselves to maintain the opportunity for dialogue, or whether they assert their autonomy by breaking away. For example, members of the women's advice centre were influential in forming a women's network to promote dialogue and shape strategy away from the constraints of official forums; a senior citizens forum was under threat as official bodies created alternative structures where they had more control over membership.

Struggles over legitimacy and control are negotiated in the everyday processes through which officials engage with groups. Our study has highlighted the importance of studying the micropolitics of engagement amongst forum members and between forums and official bodies and we have elaborated on this elsewhere (Barnes et al. 2003).

\section{The process of deliberation: particularity, difference and dissent}

It became apparent through our studies of individual initiatives that the different purposes and origins of each participation initiative will affect the nature of exchange. It was also evident that there were tensions between the institutional contexts within which conditions of participation were framed and the struggle for recognition amongst excluded groups. We concluded that such forums can be seen as the site for the development of new discourses that are negotiated along the citizen/official continuum, suggesting that deliberative forums are sites in which identity is constituted rather than expressed.

The social services user group illustrated tensions concerning purpose that were evident in responses to the nature of exchanges within the forum. The purpose was described as enabling a voice for users of social care services. Members contested whether voice should be understood as individual advocacy, personal testimony or collective action with specific change objectives. Some spoke of the importance of the forum as a site in which experiential knowledge, expressed in personal accounts, could be exchanged. Others saw this as inadequate as a basis for achieving change and there was little evidence of testimony informing more general campaigns. Evidence suggested that the social services department concerned was content to 
support the group as a forum, which could enable access to useful experiential knowledge relevant to "safe" issues (such as the design of identity cards for Orange Badge holders), rather than encourage more challenging responses on broader issues of policy (including resource allocation).

This initiative study also illuminated the complexity of diversity issues in deliberative forums. It included different interests within the constitution of the group (the range of community care "client" groups), as well as different perspectives (see Young 2000). The forced resignation of a previous chair on the grounds of racism had created selfconsciousness about language. One interviewee suggested there had been a sophisticated debate about how a sub-group of minority ethnic members should be described and how this would affect who would identify with the group. Others were reluctant to speak explicitly about this issue, indicating the difficulty experienced in engaging with conflict along these lines. The actual constitution of the group was also affected by an earlier fracturing. Mental health service users had "fallen out" with others. The institutional location of the group within local government rather than the health service also meant that many of the most important issues for this group could not be addressed in this context. In this instance, the substance of deliberations was framed by the institutional location of the forum. This in turn marginalised issues of central importance to some putative members.

One of the area committees illustrated the tensions associated with bringing together representative and participative democracy. The purpose was to enhance democracy and devolve decision making. As committees of the council they are subject to the rules and conditions that regulate council conduct. Membership comprises councillors from relevant wards, independent advisory members from local communities or voluntary organisations, representatives of key public organisations and co-opted members. Only elected councillors have voting rights. Any member of the public can attend meetings. The substance of dialogue was 'small issues: rats, rubbish and road safety': issues of considerable importance in the day-to-day lives of local residents. The council's failure to resolve these issues was one source of frustration leading to angry exchanges. A sub-text here was that attempts to engage on more strategic issues within the committee had been unsuccessful.
But the nature of exchanges reflected intercouncillor and councillor/officer dynamics in other contexts, exacerbated by tactical "alliance making" with members of the public. Councillors always had the first opportunity to speak and the capacity of the public to contribute was limited by the failure to distribute information in advance. Whilst lay knowledge was valued for providing different insights and a source of challenge, there was evidence of councillors using their power to limit debate. When councillors felt challenged by members of the public they took this out on officers; when members of the public complained about lack of resources going into their wards councillors supported this. Officers regarded councillors as their audience, rather than the public and this frustrated officer accountability to the public.

Deliberation within autonomous groups could be very different. For example, in a senior citizens' forum exchanges illustrated the significance of Young's concept of "greeting" as an important element of deliberation: 'Greeting, ... names communicative political gestures through which those who have conflicts aim to solve problems, recognize others as included in the discussion, especially those with whom they differ in opinion, interest, or social location' (Young 2000: 61). There were frequent references to the friendliness, respect, tolerance and humour evident here. Before the meetings there were jokes and anecdotes and after formal business people stayed to share tea. Participants felt this enabled strong views to be expressed and disagreement to be negotiated without falling out. The group exercised discipline over members, but also offered support, for example when an African member of the group had been subjected to racist abuse at an annual general meeting of the group.

\section{The rules of engagement}

An important aspect of our study was the dynamics of the prevailing institutional and policy context with reference to New Labour's agenda for public participation. Our analysis of the range of public participation initiatives within each of the cities led us to conclude that notwithstanding the dominance of central government in the UK, local variation in public participation is important and remains very much in evidence. This local variation is stimulated by the prevailing local context and the emergence of multi-level governance that facilitates access to 
additional sites of decision making parallel to the central state (Sullivan et al., forthcoming).

The formulation and application of rules within new deliberative forums and how this is affected by institutional context was an important consideration for us in our examination of whether and how the public could inform the rules of deliberation and what difference this made. There were four key points in the life of a public participation initiative at which rules could be seen to facilitate and/or constrain public participation.

\subsection{Access rules}

Access rules delimited participation in forums by describing who the forum was intended to engage. Those forums that aimed to be most open were experienced as the most exclusive. This was the case in the youth conference discussed above. This suggested that in very diverse communities inclusive forums based on single identities such as age may not be viable.

Organisations also influenced access through the ways they promoted forums, for example publicising their existence within known networks or targeting service users whose interests "fitted" with the organisations' priorities. For example, doctors reserved the right to vet new members of the surgery patients' group and the MEGC required that members demonstrated their accountability and representativeness before they were granted access.

Many forums developed additional rules to classify membership. In one local authority area forum participation was open to all residents but membership was restricted to elected councillors and appointed "lay members". Other forums distinguished between ordinary members and those elected or co-opted to officer roles. Access to the positions was determined by election from amongst the wider membership at an annual meeting for example, or by agreement amongst the other officers on the committee/steering group.

\subsection{Agenda setting}

Agenda setting was contested in forums where citizens felt relatively powerless and mistrusting of the sponsoring organisation. In the youth forum where officials considered agenda setting to be uncontentious, citizens experienced this as offering limited opportunities for deliberation within an officially determined framework. Elsewhere, agenda setting was a formal process between officers of the forum and respective officials. Issues got onto the agenda by being raised at past meetings, being a standing item or by request from the sponsoring organisation. In autonomous forums agenda setting was undertaken in a more collective way. For example, in the women's group agenda setting took place annually at a weekend event that combined business with social activities.

\subsection{Rules and norms in deliberation}

Institutions comprise rules (the formal expression of regulation) and norms (the informal expression of "appropriate" behaviour). Elsewhere (Sullivan et al. forthcoming), we have illustrated how dominant logics of appropriate behaviour interact with formal rules to guide the conduct of both citizens and officials in deliberative forums. The evidence of our initiative studies suggested that citizens were increasingly reluctant to play the role expected of them by officials because of a loss of trust in officials' expertise.

While officials sought to impose rules of deliberation, citizens often challenged this. For example, in an area forum, one individual regularly sought to take advantage of public question time by refusing to stick to his one (allowed) question, while in the youth forum one individual consistently challenged officials' motivations and credibility to try and shift control into the hands of young people. The consequences for each were different and related to their power and position within the forum. The area forum individual was considered a "committee anorak" and had little sympathy either from the chair or other citizens. The young person had considerable influence as he had a constituency of young people who saw him as their leader. As such he held the balance of power in the forum.

The purpose of rules was also contested. In statutory sponsored forums citizens often argued that rules existed to protect statutory bodies rather than to support participation. This was disputed by officials who believed that people 'needed to learn how to play by the rules' if they were to exercise influence. By contrast, in autonomous forums rules were discussed in terms of how they facilitated action rather than how they maintained the position of one group over another. For example, in a senior citizens' forum the emphasis was upon all members understanding the rules so as to maximise participation. 


\section{Institutions, dialogue and outcomes}

Few significant policy outcomes followed deliberation within our study period. Sometimes tension arising from the interplay of competing rules and norms meant that citizens exited the forum. In most cases citizens and officials continued to work together despite limited progress. Citizens thought small steps forward were to be expected given the institutional constraints. Little victories, like the acceptance of the forums' right to be consulted, were perceived as the first steps to more long-term change. However, for other forums their impact on the statutory sector had lessened over time as they had become "institutionalised" in their relationship. Fundamental to the achievement of different outcomes was the preparedness of statutory bodies to make change and in the area forum officials and citizens were increasingly aware of the limited power to act granted to the forum by the sponsoring agency.

Our research suggested that a key factor in achieving meaningful dialogue was the nature of rule making and the degree of involvement of citizen participants at this point. Where citizens were part of the rule making their allegiance to the rules increased and considerable attention was given to communicating rules and debating rule changes, for example the Older People's Forums. Where citizens were not part of the rule making their allegiance was limited and their engagement with rule changes minimal, for example the local authority area committees. This is significant as without the wider interaction of agents with rules, future institutional change (and hence more meaningful dialogue) is unlikely.

\section{Conclusion}

By exploring participation from the perspectives of both citizens and officials and by studying the process of deliberation in a number of study sites, we have highlighted the rich diversity and dynamic and interactive nature of participation in England.

We are able to conclude that public participation initiatives can be both facilitated and constrained by their operation in a "developed" state context. Our research has shown that the power, capacity and resources available to the state can be marshalled to support an agenda for change in such a way as to secure the swift development of new initiatives in a variety of arenas. However, the inability (and reluctance) of many institutional players to change the way in which they operate can result in public participation initiatives that are bound by rules and structures that fit officials' expectations of how things should be done, but are correspondingly alien to public participants. This is compounded by the fact that very few statesponsored initiatives actually challenge the prevailing power relationship between "the public" and "the officials", resulting in little material change to decision making, a "buying off" or deflection of any citizen opposition and a demoralisation and even alienation of once-committed citizen participants.

Following on from this, our research has confirmed that even within a "developed" state, there remains a corresponding need for citizens to develop free or "popular spaces" in which alternative discourses and approaches can be developed. On some occasions these "popular spaces" may combine with state-sponsored bodies, while in other circumstances "popular spaces" may retain an "arms length" relationship with state institutions. However, the capacity to develop an independent existence is vitally important to the health of a democratic society.

This study has alerted us to particular areas of further investigation into deliberation and public participation that could be usefully exploited in the future. Data from this project has highlighted the process outcomes of deliberative forums, that is, their impact on institutional norms and the shaping of new patterns of relationship between the public sector and citizens/users. However, it has not been possible to identify concrete links between public participation in deliberative forums and specific policy impacts. Assessing policy outcomes through a longitudinal study of a cross section of public participation initiatives such as those covered in our study would fill this important gap in the research evidence. A parallel project exploring deliberation at different tiers of governance would offer interesting insights into the relationship between deliberative processes at different levels of decision making. Together with further comparative work across different political contexts, with differently structured and developed state systems, this could help promote greater understandings of the political dynamics of participation in practice. 


\section{Notes}

1. Birmingham (pop. 977,091) and Liverpool (pop. 439,476 ) were chosen for a number of contrasting features, which include: different political profiles (Birmingham with a longstanding Labour administration in contrast to Liverpool's rather more turbulent political history which has recently seen the Liberal Democrats wrest power from Labour); differences in racial composition at 20 per cent and 5 per cent Black and ethnic minority populations, respectively; and different ranks on an index of deprivation in England, at 23rd and 3rd, respectively.

2. The first phase of the research involved surveying the two cities to establish the range and types of deliberative

\section{References}

Barnes, M., 1997, Care, Communities and Citizens, Harlow: Addison Wesley Longman

Barnes, M. and Bowl, R., 2001, Taking Over the Asylum. Empowerment and Mental Health, Basingstoke: Palgrave

Barnes, M. and Prior, D., 2000, Private Lives as Public Policy, Birmingham: Venture Press

Barnes, M., Newman, J., Knops, A. and Sullivan, H., 2003, "Constituting "the public" in public participation', Public Administration, Vol 81 No 2: 379-99

Cockburn, C., 1977, The Local State, London: Pluto Press

Fraser, N., 1997, Justice Interruptus. Critical Reflections on the "Postsocialist" Condition, New York: Routledge

Lister, R., 1997, Citizenship: Feminist Perspectives, Basingstoke: Palgrave

Lowndes, V., Stoker, G., Pratchett, L., Wilson, D., Leach, S. and Wingfield, M., 1998, Enhancing Public Participation in Local Government, London: Department of Environment, Transport and the Regions (DETR)

Melucci, A., 1996, Challenging Codes: Collective Action in the Information Age, Cambridge: Cambridge University Press forums in existence. We received information about 71 examples of participation initiatives in Birmingham and 30 in Liverpool, the smaller of the two cities. We then conducted 17 detailed case studies across the two cities, selected to address our research questions across a range of types of initiative. In each of the 17 initiatives, we undertook observation and conducted semi-structured interviews with both citizen and official participants.

3. The research was funded by the Economic and Social Science Research Council as part of its 'Democracy and Participation Programme'. Our research project 'Power, Participation and Political Renewal' was award No L215252001.

Newman, J., 2001, Modernising Governance. New Labour, Policy and Society, London: Sage

Office of the Deputy Prime Minister (ODPM), 2002, Public Participation in Local Government: A Survey of Local Authorities, London: ODPM

Prior, D. Stewart, J. and Walsh, K., 1995, Citizenship: Rights, Community and Participation, London: Pitman

Social Exclusion Unit, 2001, A New Commitment to Neighbourhood Renewal, National Strategy Action Plan, London: The Stationery Office

Sullivan, H. and Skelcher, C., 2002, Working Across Boundaries: Collaboration in Public Services, Basingstoke: Palgrave

Sullivan, H., Knops, A., Barnes, M. and Newman, J., forthcoming, 'Central-local relations in an era of multi-level governance: the case of public participation policy in England, 1997-2001', Local Government Studies

Touraine, A., 2000, Can We Live Together? Equality and Difference, Cambridge: Polity Press

Young, I.M., 2000, Inclusion and Democracy, Oxford: Oxford University Press 